\title{
Iterative schemes for approximating solution of nonlinear operators in Banach spaces
}

\author{
Siwaporn Saewan ${ }^{1 *}$, Preedaporn Kanjanasamranwong ${ }^{1 *}$, Poom Kumam ${ }^{2 *}$ and Yeol Je Cho ${ }^{3 *}$
}

"Correspondence:

si_wa_pon@hotmail.com;

siwaporn@tsu.ac.th;

preedaporn@tsu.ac.th;

poom.kum@kmutt.ac.th;

yjcho@gnu.ac.kr

'Department of Mathematics and

Statistics, Faculty of Science, Thaksin

University, Phatthalung, 93110,

Thailand

2Department of Mathematics,

Faculty of Science, King Mongkut's University of Technology Thonburi,

Bangmod, Thrungkru, Bangkok, 10140, Thailand

Full list of author information is available at the end of the article

\begin{abstract}
The purpose of this paper is to present a new modified Halpern-Mann type iterative scheme by using the generalized $f$-projection operator for finding a common element in the set of zeroes of a system of maximal monotone operators, the set of fixed points of a totally quasi- $\phi$-asymptotically nonexpansive mapping and the set of solutions of a system of generalized Ky Fan's inequalities in a uniformly smooth and strictly convex Banach space with the Kadec-Klee property. Furthermore, we show that our proposed iterative scheme converges strongly to a common element of the sets mentioned above.
\end{abstract}

MSC: $47 \mathrm{H} 05 ; 47 \mathrm{H} 09 ; 47 \mathrm{H} 10$

Keywords: generalized $f$-projection operators; system of generalized Ky Fan's inequalities; totally quasi- $\phi$-asymptotically nonexpansive mapping; variational inequalities; maximal monotone operators

\section{Introduction}

In 1972, Ky Fan's inequalities were first introduced by Fan [1]. The study concerning Ky Fan's inequalities, fixed points of nonlinear mappings and their approximation algorithms constitutes a topic of intensive research efforts. Many well-known problems arising in various branches of science can be studied by using algorithms which are iterative in their nature. As an example, in computer tomography with limited data, each piece of information implies the existence of a convex set in which the required solution lies.

Many authors have considered a family of nonexpansive mappings to show the existence of fixed points and related topics. Especially, the well-known convex feasibility problem reduces to finding a point in the intersection of the fixed point sets of a family of nonexpansive mappings and the problem of finding an optimal point that minimizes a given cost function over the set of common fixed points of a family of nonexpansive mappings.

Solving the convex feasibility problem for a system of generalized Ky Fan's inequalities is very general in the sense that it includes, as special cases, optimization problems, equilibrium problems, variational inequality problems, minimax problems. Moreover, the generalized Ky Fan's inequality was shown in [2] to cover monotone inclusion problems, saddle point problems, variational inequality problems, minimization problems, optimization problems, vector equilibrium problems, Nash equilibria in noncooperative games. In other words, the generalized Ky Fan's inequality and equilibrium problem are a unified model for several problems arising in physics, engineering, science, optimization, economics and related topics.

(c) 2013 Saewan et al: licensee Springer. This is an Open Access article distributed under the terms of the Creative Commons Attribution License (http://creativecommons.org/licenses/by/2.0), which permits unrestricted use, distribution, and reproduction in any medium, provided the original work is properly cited. 
One of the most interesting and important problems in the theory of maximal monotone operators is to find a zero point of maximal monotone operators. This problem contains the convex minimization problem and the variational inequality problem. A popular method for approximating this problem is called the proximal point algorithm introduced by Martinet [3] in a Hilbert space. In 1976, Rockafellar [4] extended the knowledge of Martinet [3] and proved weak convergence of the proximal point algorithm. The proximal point algorithm of Rockafellar [4] is a successful algorithm for finding a zero point of maximal monotone operators. Thereafter, many papers have shown convergence theorems of the proximal point algorithm in various spaces (see [5-14]).

A point $x \in C$ is a fixed point of $S$ provided $S x=x$. We denote by $F(S)$ the fixed point set of $S$, that is, $F(S)=\{x \in C: S x=x\}$. A point $p$ in $C$ is called an asymptotic fixed point of $S$ [15] if $C$ contains a sequence $\left\{x_{n}\right\}$ which converges weakly to $p$ such that $\lim _{n \rightarrow \infty}\left\|x_{n}-S x_{n}\right\|=0$. The set of asymptotic fixed points of $S$ is denoted by $\widehat{F}(S)$. Recently, Halpern and Mann iterative algorithms have been considered for approximations of common fixed points by many authors. For example, in 2011, Saewan and Kumam [16] introduced a modified Mann iterative scheme by using the generalized $f$-projection method for approximating a common fixed point of a countable family of relatively quasi-nonexpansive mappings. Chang et al. [17] considered a modified Halpern iterative scheme for approximating a common fixed point for a totally quasi- $\phi$-asymptotically nonexpansive mapping. Recently, Li et al. [18] introduced a hybrid iterative scheme for approximation of a fixed point of relatively nonexpansive mappings by using the properties of generalized $f$-projection operators in a uniformly smooth real Banach space, which is also uniformly convex, and proved some strong convergence theorems for the hybrid iterative scheme.

On the other hand, Ofoedu and Shehu [19] extended the algorithm of Li et al. [18] to prove strong convergence theorems for a common solution of the set of solutions of a system of Ky Fan's inequalities and the set of common fixed points of a pair of relatively quasi-nonexpansive mappings in a Banach space by using the generalized $f$-projection operator. Chang et al. [20] extended and improved the results of Qin and Su [21] to obtain strong convergence theorems for finding a common element of the set of solutions for a generalized Ky Fan's inequality, the set of solutions for a variational inequality problem and the set of common fixed points for a pair of relatively nonexpansive mappings in a Banach space.

Motivated and inspired by the work mentioned above, in this paper, we introduce a new hybrid iterative scheme of the generalized $f$-projection operator based on the HalpernMann type iterative scheme for finding a common element of the set of zeroes of a system of maximal monotone operators, the set of fixed points of a totally quasi- $\phi$-asymptotically nonexpansive mapping and the set of solutions of a system of generalized Ky Fan's inequalities in a uniformly smooth and strictly convex Banach space with the Kadec-Klee property.

\section{Preliminaries}

A Banach space $E$ with the norm $\|\cdot\|$ is called strictly convex if $\left\|\frac{x+y}{2}\right\|<1$ for all $x, y \in U$ with $x \neq y$, where $U=\{x \in E:\|x\|=1\}$ is the unit sphere of $E$. A Banach space $E$ is called smooth if the limit

$$
\lim _{t \rightarrow 0} \frac{\|x+t y\|-\|x\|}{t}
$$


exists for each $x, y \in U$. It is also called uniformly smooth if the limit exists uniformly for all $x, y \in U$. In this paper, we denote the strong convergence and weak convergence of a sequence $\left\{x_{n}\right\}$ by $x_{n} \rightarrow x$ and $x_{n} \rightarrow x$, respectively.

Let $E$ be a real Banach space with the dual space $E^{*}$ and let $C$ be a nonempty closed and convex subset of $E$. A mapping $S: C \rightarrow C$ is said to be:

(1) nonexpansive if

$$
\|S x-S y\| \leq\|x-y\|
$$

for all $x, y \in C$;

(2) quasi-nonexpansive if $F(S) \neq \emptyset$ and

$$
\|S x-y\| \leq\|x-y\|
$$

for all $x \in C$ and $y \in F(S)$;

(3) asymptotically nonexpansive if there exists a sequence $\left\{k_{n}\right\} \subset[1, \infty)$ with $k_{n} \rightarrow 1$ as $n \rightarrow \infty$ such that

$$
\left\|S^{n} x-S^{n} y\right\| \leq k_{n}\|x-y\|
$$

for all $x, y \in C$;

(4) asymptotically quasi-nonexpansive if $F(S) \neq \emptyset$ and there exists a sequence $\left\{k_{n}\right\} \subset[1, \infty)$ with $k_{n} \rightarrow 1$ as $n \rightarrow \infty$ such that

$$
\left\|S^{n} x-y\right\| \leq k_{n}\|x-y\|
$$

for all $x \in C$ and $y \in F(S)$;

(5) totally asymptotically nonexpansive if there exist nonnegative real sequences $\left\{v_{n}\right\}$, $\left\{\mu_{n}\right\}$ with $v_{n} \rightarrow 0, \mu_{n} \rightarrow 0$ as $n \rightarrow \infty$ and a strictly increasing continuous function $\psi: \mathbf{R}^{+} \rightarrow \mathbf{R}^{+}$with $\psi(0)=0$ such that

$$
\left\|S^{n} x-S^{n} y\right\| \leq\|x-y\|+\mu_{n} \psi(\|x-y\|)+v_{n}
$$

for all $x, y \in C$ and $n \geq 1$.

A mapping $S: C \rightarrow C$ is said to be uniformly L-Lipschitz continuous if there exists a constant $L>0$ such that

$$
\left\|S^{n} x-S^{n} y\right\| \leq L\|x-y\|
$$

for all $x, y \in C$. A mapping $S: C \rightarrow C$ is said to be closed if, for any sequence $\left\{x_{n}\right\} \subset C$ such that $\lim _{n \rightarrow \infty} x_{n}=x_{0}$ and $\lim _{n \rightarrow \infty} S x_{n}=y_{0}$, we have $S x_{0}=y_{0}$.

The normalized duality mapping $J: E \rightarrow 2^{E^{*}}$ is defined by

$$
J(x)=\left\{x^{*} \in E^{*}:\left\langle x, x^{*}\right\rangle=\|x\|^{2},\left\|x^{*}\right\|=\|x\|\right\}
$$


for all $x \in E$. If $E$ is a Hilbert space, then $J=I$, where $I$ is the identity mapping. Consider the functional $\phi: E \times E \rightarrow \mathbf{R}$ defined by

$$
\phi(x, y)=\|x\|^{2}-2\langle x, J y\rangle+\|y\|^{2},
$$

where $J$ is the normalized duality mapping and $\langle\cdot, \cdot\rangle$ denotes the duality pairing of $E$ and $E^{*}$. If $E$ is a Hilbert space, then $\phi(y, x)=\|y-x\|^{2}$. It is obvious from the definition of $\phi$ that

$$
(\|y\|-\|x\|)^{2} \leq \phi(y, x) \leq(\|y\|+\|x\|)^{2}
$$

for all $x, y \in E$.

A mapping $S: C \rightarrow C$ is said to be:

(1) relatively nonexpansive $[22,23]$ if $\hat{F}(S)=F(S)$ and

$$
\phi(p, S x) \leq \phi(p, x)
$$

for all $x \in C$ and $p \in F(S)$;

(2) relatively asymptotically nonexpansive [24] if $\hat{F}(S)=F(S) \neq \emptyset$ and there exists a sequence $\left\{k_{n}\right\} \subset[1, \infty)$ with $k_{n} \rightarrow 1$ as $n \rightarrow \infty$ such that

$$
\phi\left(p, S^{n} x\right) \leq k_{n} \phi(p, x)
$$

for all $x \in C, p \in F(S)$ and $n \geq 1$;

(3) $\phi$-nonexpansive $[25,26]$ if

$$
\phi(S x, S y) \leq \phi(x, y)
$$

for all $x, y \in C$;

(4) quasi- $\phi$-nonexpansive $[25,26]$ if $F(S) \neq \emptyset$ and

$$
\phi(p, S x) \leq \phi(p, x)
$$

for all $x \in C$ and $p \in F(S)$;

(5) asymptotically $\phi$-nonexpansive [26] if there exists a sequence $\left\{k_{n}\right\} \subset[0, \infty)$ with $k_{n} \rightarrow 1$ as $n \rightarrow \infty$ such that

$$
\phi\left(S^{n} x, S^{n} y\right) \leq k_{n} \phi(x, y)
$$

for all $x, y \in C$ and $n \geq 1$;

(6) quasi- $\phi$-asymptotically nonexpansive [26] if $F(S) \neq \emptyset$ and there exists a sequence $\left\{k_{n}\right\} \subset[0, \infty)$ with $k_{n} \rightarrow 1$ as $n \rightarrow \infty$ such that

$$
\phi\left(p, S^{n} x\right) \leq k_{n} \phi(p, x)
$$

for all $x \in C, p \in F(S)$ and $n \geq 1$; 
(7) totally quasi- $\phi$-asymptotically nonexpansive if $F(S) \neq \emptyset$ and there exist nonnegative real sequences $\left\{v_{n}\right\},\left\{\mu_{n}\right\}$ with $v_{n} \rightarrow 0, \mu_{n} \rightarrow 0$ as $n \rightarrow \infty$ and a strictly increasing continuous function $\psi: \mathbf{R}^{+} \rightarrow \mathbf{R}^{+}$with $\psi(0)=0$ such that

$$
\phi\left(p, S^{n} x\right) \leq \phi(p, x)+v_{n} \psi(\phi(p, x))+\mu_{n}
$$

for all $x \in C, p \in F(S)$ and $n \geq 1$.

Lemma 1 [27] Let $C$ be a nonempty closed and convex subset of a uniformly smooth and strictly convex Banach space $E$ with the Kadec-Klee property. Let $S: C \rightarrow C$ be a closed and totally quasi- $\phi$-asymptotically nonexpansive mapping with nonnegative real sequences $\left\{v_{n}\right\}$ and $\left\{\mu_{n}\right\}$ with $v_{n} \rightarrow 0$ and $\mu_{n} \rightarrow 0$ as $n \rightarrow \infty$, respectively, and a strictly increasing continuous function $\zeta: \mathbf{R}^{+} \rightarrow \mathbf{R}^{+}$with $\zeta(0)=0$. If $\mu_{1}=0$, then the set $F(S)$ of fixed points of $S$ is a closed convex subset of $C$.

Alber [28] introduced that the generalized projection $\Pi_{C}: E \rightarrow C$ is a mapping that assigns to an arbitrary point $x \in E$ the minimum point of the functional $\phi(x, y)$, that is, $\Pi_{C} x=\bar{x}$, where $\bar{x}$ is the solution of the minimization problem

$$
\phi(\bar{x}, x)=\inf _{y \in C} \phi(y, x)
$$

The existence and uniqueness of the operator $\Pi_{C}$ follows from the properties of the functional $\phi(y, x)$ and strict monotonicity of the mapping $J$ (see, for example, [28-32]).

If $E$ is a Hilbert space, then $\phi(x, y)=\|x-y\|^{2}$ and $\Pi_{C}$ becomes the metric projection $P_{C}: H \rightarrow C$. If $C$ is a nonempty closed and convex subset of a Hilbert space $H$, then $P_{C}$ is nonexpansive.

Remark 1 The basic properties of a Banach space $E$ related to the normalized duality mapping $J$ are as follows (see [30]):

(1) If $E$ is an arbitrary Banach space, then $J$ is monotone and bounded;

(2) If $E$ is a strictly convex Banach space, then $J$ is strictly monotone;

(3) If $E$ is a smooth Banach space, then $J$ is single-valued and semicontinuous;

(4) If $E$ is a uniformly smooth Banach space, then $J$ is uniformly norm-to-norm continuous on each bounded subset of $E$;

(5) If $E$ is a reflexive smooth and strictly convex Banach space, then the normalized duality mapping $J$ is single-valued, one-to-one and onto;

(6) If $E$ is a reflexive strictly convex and smooth Banach space and $J$ is the duality mapping from $E$ into $E^{*}$, then $J^{-1}$ is also single-valued, bijective and is also the duality mapping from $E^{*}$ into $E$, and thus $J J^{-1}=I_{E^{*}}$ and $J^{-1} J=I_{E}$;

(7) If $E$ is a uniformly smooth Banach space, then $E$ is smooth and reflexive;

(8) $E$ is a uniformly smooth Banach space if and only if $E^{*}$ is uniformly convex;

(9) If $E$ is a reflexive and strictly convex Banach space, then $J^{-1}$ is norm-weak" -continuous.

Remark 2 If $E$ is a reflexive, strictly convex and smooth Banach space, then $\phi(x, y)=0$ if and only if $x=y$. It is sufficient to show that if $\phi(x, y)=0$, then $x=y$. From (2) we 
have

$$
\begin{aligned}
0 & =\|x\|^{2}-2\langle x, J y\rangle+\|y\|^{2} \\
& =\|x\|^{2}-2\|x\|\|J y\|+\|y\|^{2} \\
& =\|x\|^{2}-2\|x\|\|J y\|+\|y\|^{2} \\
& =\|x-y\|^{2} .
\end{aligned}
$$

That is, $\|x\|=\|y\|$. This implies that $\langle x, J y\rangle=\|x\|^{2}=\|J y\|^{2}$. From the definition of $J$, one has $J x=J y$. Therefore, we have $x=y$ (see [30,32, 33] for more details).

In 2006, Wu and Huang [34] introduced a new generalized $f$-projection operator in a Banach space. They extended the definition of the generalized projection operators introduced by Abler [35] and proved some properties of the generalized $f$-projection operator. Consider the functional $G: C \times E^{*} \rightarrow \mathbf{R} \cup\{+\infty\}$ defined by

$$
G(y, \varpi)=\|y\|^{2}-2\langle y, \varpi\rangle+\|\varpi\|^{2}+2 \rho f(y)
$$

for all $(y, \varpi) \in C \times E^{*}$, where $\rho$ is a positive number and $f: C \rightarrow \mathbf{R} \cup\{+\infty\}$ is proper, convex and lower semicontinuous. From the definition of $G, \mathrm{Wu}$ and Huang [34] proved the following properties:

(1) $G(y, \varpi)$ is convex and continuous with respect to $\varpi$ when $y$ is fixed;

(2) $G(y, \varpi)$ is convex and lower semicontinuous with respect to $y$ when $\varpi$ is fixed.

Definition 1 Let $E$ be a real Banach space with its dual space $E^{*}$ and let $C$ be a nonempty closed and convex subset of $E$. We say that $\pi_{C}^{f}: E^{*} \rightarrow 2^{C}$ is a generalized $f$-projection operator if

$$
\pi_{C}^{f} \varpi=\left\{u \in C: G(u, \varpi)=\inf _{y \in C} G(y, \varpi), \forall \varpi \in E^{*}\right\} .
$$

Recall that a Banach space $E$ has the Kadec-Klee property [30, 32, 36] if for any sequence $\left\{x_{n}\right\} \subset E$ and $x \in E$ with $x_{n} \rightarrow x$ and $\left\|x_{n}\right\| \rightarrow\|x\|$, we have $\left\|x_{n}-x\right\| \rightarrow 0$ as $n \rightarrow \infty$. It is well known that if $E$ is a uniformly convex Banach space, then $E$ has the Kadec-Klee property.

Lemma 2 [34] Let E be a real reflexive Banach space with its dual space $E^{*}$ and let $C$ be a nonempty closed and convex subset of $E$. The following statements hold:

(1) $\pi_{C}^{f} \varpi$ is a nonempty, closed and convex subset of $C$ for all $\varpi \in E^{*}$;

(2) If $E$ is smooth, then for all $\varpi \in E^{*}, x \in \pi_{C}^{f} \varpi$ if and only if

$$
\langle x-y, \varpi-J x\rangle+\rho f(y)-\rho f(x) \geq 0
$$

for all $y \in C$;

(3) If $E$ is strictly convex and $f: C \rightarrow \mathbf{R} \cup\{+\infty\}$ is positive homogeneous (i.e., $f(t x)=t f(x)$ for all $t>0$ such that $t x \in C$, where $x \in C)$, then $\pi_{C}^{f} \varpi$ is a single-valued mapping. 
Recently, Fan et al. [37] showed that the condition, $f$ is positive homogeneous, which appears in [37, Lemma 2.1(iii)], can be removed.

Lemma 3 [37] Let E be a real reflexive Banach space with its dual space $E^{*}$ and let $C$ be a nonempty closed and convex subset of $E$. If $E$ is strictly convex, then $\pi_{C}^{f} \varpi$ is single-valued.

Recall that $J$ is a single-valued mapping when $E$ is a smooth Banach space. There exists a unique element $\varpi \in E^{*}$ such that $\varpi=J x$, where $x \in E$. This substitution in (5) gives the following:

$$
G(y, J x)=\|y\|^{2}-2\langle y, J x\rangle+\|x\|^{2}+2 \rho f(y) .
$$

Now, we consider the second generalized $f$ projection operator in a Banach space (see [18]).

Definition 2 Let $E$ be a real smooth Banach space and let $C$ be a nonempty closed and convex subset of $E$. We say that $\Pi_{C}^{f}: E \rightarrow 2^{C}$ is a generalized $f$-projection operator if

$$
\Pi_{C}^{f} x=\left\{u \in C: G(u, J x)=\inf _{y \in C} G(y, J x), \forall x \in E\right\} .
$$

Lemma 4 [38] Let $E$ be a Banach space and let $f: E \rightarrow \mathbf{R} \cup\{+\infty\}$ be a lower semicontinuous and convex function. Then there exist $x^{*} \in E^{*}$ and $\alpha \in \mathbf{R}$ such that

$$
f(x) \geq\left\langle x, x^{*}\right\rangle+\alpha
$$

for all $x \in E$.

Lemma 5 [18] Let $E$ be a reflexive smooth Banach space and let $C$ be a nonempty closed and convex subset of $E$. The following statements hold:

(1) $\Pi_{C}^{f} x$ is a nonempty closed and convex subset of $C$ for all $x \in E$;

(2) For all $x \in E, \hat{x} \in \Pi_{C}^{f} x$ if and only if

$$
\langle\hat{x}-y, J x-J \hat{x}\rangle+\rho f(y)-\rho f(\hat{x}) \geq 0
$$

for all $y \in C$;

(3) If $E$ is strictly convex, then $\Pi_{C}^{f}$ is a single-valued mapping.

Lemma 6 [18] Let $E$ be a real reflexive smooth Banach space and let $C$ be a nonempty closed and convex subset of $E$. Then, for any $x \in E$ and $\hat{x} \in \Pi_{C}^{f}$,

$$
\phi(y, \hat{x})+G(\hat{x}, J x) \leq G(y, J x)
$$

for all $y \in C$.

Lemma 7 [18] Let $E$ be a Banach space and let $f: E \rightarrow \mathbf{R} \cup\{+\infty\}$ be a proper, convex and lower semicontinuous mapping with convex domain $D(f)$. If $\left\{x_{n}\right\}$ is a sequence in $D(f)$ such that $x_{n} \rightarrow \hat{x} \in D(f)$ and $\lim _{n \rightarrow \infty} G\left(x_{n}, J y\right)=G(\hat{x}, J y)$, then $\lim _{n \rightarrow \infty}\left\|x_{n}\right\|=\|\hat{x}\|$. 
Remark 3 Let $E$ be a uniformly convex and uniformly smooth Banach space and $f(y)=0$ for all $y \in E$. Then Lemma 6 reduces to the property of the generalized projection operator considered by Alber [28].

If $f(y) \geq 0$ for all $y \in C$ and $f(0)=0$, then the definition of a totally quasi- $\phi$-asymptotically nonexpansive $S$ is equivalent to the following:

For $F(S) \neq \emptyset$ and there exist nonnegative real sequences $\left\{v_{n}\right\},\left\{\mu_{n}\right\}$ with $v_{n} \rightarrow 0, \mu_{n} \rightarrow 0$ as $n \rightarrow \infty$, respectively, and a strictly increasing continuous function $\psi: \mathbf{R}^{+} \rightarrow \mathbf{R}^{+}$with $\psi(0)=0$ such that

$$
G\left(p, S^{n} x\right) \leq G(p, x)+v_{n} \psi G(p, x)+\mu_{n}
$$

for all $x \in C, p \in F(S)$ and $n \geq 1$.

Let $\theta$ be a bifunction from $C \times C$ to $\mathbf{R}$, where $\mathbf{R}$ denotes the set of real numbers. The equilibrium problem (for short, (EP)) is to find $\hat{x} \in C$ such that

$$
\theta(\hat{x}, y) \geq 0
$$

for all $y \in C$. The set of solutions of (EP) (7) is denoted by $\mathrm{EP}(\theta)$.

For solving the equilibrium problem for a bifunction $\theta: C \times C \rightarrow \mathbf{R}$, let us assume that $\theta$ satisfies the following conditions:

(A1) $\theta(x, x)=0$ for all $x \in C$;

(A2) $\theta$ is monotone, i.e., $\theta(x, y)+\theta(y, x) \leq 0$ for all $x, y \in C$;

(A3) for all $x, y, z \in C$,

$$
\lim _{t \downarrow 0} \theta(t z+(1-t) x, y) \leq \theta(x, y) ;
$$

(A4) for all $x \in C, y \mapsto \theta(x, y)$ is convex and lower semicontinuous.

For example, let $B$ be a continuous and monotone operator of $C$ into $E^{*}$ and define

$$
\theta(x, y)=\langle B x, y-x\rangle
$$

for all $x, y \in C$. Then $\theta$ satisfies (A1)-(A4).

Lemma 8 [2] Let $C$ be a closed convex subset of a smooth, strictly convex and reflexive Banach space $E$ and let $\theta$ be a bifunction from $C \times C$ to $\mathbf{R}$ satisfying the conditions (A1)(A4). Then, for any $r>0$ and $x \in E$, there exists $z \in C$ such that

$$
\theta(z, y)+\frac{1}{r}\langle y-z, J z-J x\rangle \geq 0
$$

for all $y \in C$.

Lemma 9 [39] Let $C$ be a closed convex subset of a uniformly smooth, strictly convex and reflexive Banach space $E$ and let $\theta$ be a bifunction from $C \times C$ to $\mathbf{R}$ satisfying the conditions (A1)-(A4). For all $r>0$ and $x \in E$, define a mapping $T_{r}^{\theta}: E \rightarrow C$ as follows:

$$
T_{r}^{\theta} x=\left\{z \in C: \theta(z, y)+\frac{1}{r}\langle y-z, J z-J x\rangle \geq 0, \forall y \in C\right\} .
$$


Then the following hold:

(1) $T_{r}^{\theta}$ is single-valued;

(2) $T_{r}^{\theta}$ is a firmly nonexpansive-type mapping [40], that is, for all $x, y \in E$,

$$
\left\langle T_{r}^{\theta} x-T_{r}^{\theta} y, J T_{r}^{\theta} x-J T_{r}^{\theta} y\right\rangle \leq\left\langle T_{r}^{\theta} x-T_{r}^{\theta} y, J x-J y\right\rangle ;
$$

(3) $F\left(T_{r}^{\theta}\right)=\mathrm{EP}(\theta)$;

(4) $\mathrm{EP}(\theta)$ is closed and convex.

Lemma 10 [39] Let $C$ be a closed convex subset of a smooth, strictly convex and reflexive Banach space $E$ and let $\theta$ be a bifunction from $C \times C$ to $\mathbf{R}$ satisfying the conditions (A1)(A4). Then, for any $r>0, x \in E$ and $q \in F\left(T_{r}^{\theta}\right)$,

$$
\phi\left(q, T_{r}^{\theta} x\right)+\phi\left(T_{r}^{\theta} x, x\right) \leq \phi(q, x) .
$$

An operator $A \subset E \times E^{*}$ is said to be monotone if

$$
\left\langle x-y, x^{\prime \prime}-y^{\prime \prime}\right\rangle \geq 0
$$

for all $\left(x, x^{*}\right),\left(y, y^{*}\right) \in A$. A point $z \in E$ is called a zero point of $A$ if

$$
0 \in A z \text {. }
$$

We denote the set of zeroes of the operator $A$ by $A^{-1} 0$, that is,

$$
A^{-1} 0=\{z \in E: 0 \in A z\} .
$$

A monotone $A \subset E \times E^{*}$ is said to be maximal if its graph $G(A)=\left\{\left(x, y^{*}\right): y^{*} \in A x\right\}$ is not property contained in the graph of any other monotone operator. If $A$ is maximal monotone, then the solution set $A^{-1} 0$ is closed and convex.

Let $E$ be a smooth strictly convex and reflexive Banach space, let $C$ be a nonempty closed convex subset of $E$ and let $A \subset E \times E^{*}$ be a monotone operator satisfying $D(A) \subset C \subset$ $J^{-1}\left(\bigcap_{\lambda>0} R(J+\lambda A)\right)$. Then the resolvent $J_{\lambda}: C \rightarrow D(A)$ of $A$ is defined by

$$
J_{\lambda} x=\{z \in D(A): J x \in J z+\lambda A z, \forall x \in C\} .
$$

$J_{\lambda}$ is a single-valued mapping from $E$ to $D(A)$. On the other hand, $J_{\lambda}=(J+\lambda A)^{-1} J$ for all $\lambda>0$.

For any $\lambda>0$, the Yosida approximation $A_{\lambda}: C \rightarrow E^{*}$ of $A$ is defined by $A_{\lambda} x=\frac{J x-J \lambda_{\lambda} x}{\lambda}$ for all $x \in C$. We know that $A_{\lambda} x \in A\left(J_{\lambda} x\right)$ for all $\lambda>0$ and $x \in E$. Since relatively quasinonexpansive mappings and quasi- $\phi$-nonexpansive mappings are the same, we can see that $J_{\lambda}$ is a quasi- $\phi$-nonexpansive mapping (see [41, Theorem 4.7]).

Lemma 11 [42] Let E be a smooth strictly convex and reflexive Banach space, let $C$ be a nonempty closed convex subset of $E$ and let $A \subset E \times E^{*}$ be a monotone operator satisfying $D(A) \subset C \subset J^{-1}\left(\bigcap_{\lambda>0} R(J+\lambda A)\right)$. For any $\lambda>0$, let $J_{\lambda}$ and $A_{\lambda}$ be the resolvent and the Yosida approximation of $A$, respectively. Then the following hold: 
(1) $\phi\left(p, J_{\lambda} x\right)+\phi\left(J_{\lambda} x, x\right) \leq \phi(p, x)$ for all $x \in C$ and $p \in A^{-1} 0$;

(2) $\left(J_{\lambda} x, A_{\lambda} x\right) \in A$ for all $x \in C$;

(3) $F\left(J_{\lambda}\right)=A^{-1} 0$.

Lemma 12 [43] Let $E$ be a reflexive strictly convex and smooth Banach space. Then an operator $A \subset E \times E^{*}$ is maximal monotone if and only if $R(J+\lambda A)=E^{*}$ for all $\lambda>0$.

\section{Main result}

Now, we give the main results in this paper.

Theorem 1 Let $C$ be a nonempty closed and convex subset of a uniformly smooth and strictly convex Banach space $E$ with the Kadec-Klee property. For each $i=1,2, \ldots, m$, let $\theta_{i}$ be a bifunction from $C \times C$ to $\mathbf{R}$ satisfying the conditions (A1)-(A4). Let $A_{j} \subset E \times E^{*}$ be a maximal monotone operator satisfying $D\left(A_{j}\right) \subset C$ and $J_{\lambda_{j, n}}^{A_{j}}=\left(J+\lambda_{j, n} A_{j}\right)^{-1} J$ for all $\lambda_{j, n}>0$ and $j=1,2, \ldots, l$. Let $S: C \rightarrow C$ be a closed and totally quasi- $\phi$-asymptotically nonexpansive mapping with nonnegative real sequences $\left\{v_{n}\right\},\left\{\mu_{n}\right\}$ with $v_{n} \rightarrow 0, \mu_{n} \rightarrow 0$ as $n \rightarrow \infty$, respectively, and a strictly increasing continuous function $\psi: \mathbf{R}^{+} \rightarrow \mathbf{R}^{+}$with $\psi(0)=0$. Let $f: E \rightarrow \mathbf{R}^{+}$be a convex and lower semicontinuous function with $C \subset \operatorname{int}(D(f))$ and $f(0)=0$. Assume that $S$ is uniformly L-Lipschitz continuous and $\mathcal{F}=F(S) \cap\left(\bigcap_{i=1}^{m} \operatorname{EP}\left(\theta_{i}\right)\right) \cap$ $\left(\bigcap_{j=1}^{l} A_{j}^{-1} 0\right) \neq \emptyset$. For any initial point $x_{1} \in E$, define $C_{1}=C$ and the sequence $\left\{x_{n}\right\}$ in $C$ by

$$
\left\{\begin{array}{l}
z_{n}=J_{\lambda_{l, n}}^{A_{l}} \circ J_{\lambda_{l-1, n}}^{A_{l-1}} \circ \cdots \circ J_{\lambda_{1, n}}^{A_{1}} x_{n}, \\
u_{n}=T_{r_{m, n}}^{\theta_{m}} \circ T_{r_{m-1, n}}^{\theta_{m-1}} \cdots \cdots \circ T_{r_{1, n}}^{\theta_{1}} z_{n}, \\
y_{n}=J^{-1}\left(\alpha_{n} J x_{1}+\beta_{n} J S^{n} x_{n}+\gamma_{n} J u_{n}\right), \\
C_{n+1}=\left\{v \in C_{n}: G\left(v, J y_{n}\right) \leq \alpha_{n} G\left(v, J x_{1}\right)+\left(1-\alpha_{n}\right) G\left(v, J x_{n}\right)+\zeta_{n}\right\}, \\
x_{n+1}=\Pi_{C_{n+1}}^{f} x_{1}
\end{array}\right.
$$

for each $n \geq 1$, where $\left\{\alpha_{n}\right\},\left\{\beta_{n}\right\}$ and $\left\{\gamma_{n}\right\}$ are the sequences in $(0,1)$ such that $\alpha_{n}+\beta_{n}+\gamma_{n}=1$, $\zeta_{n}=v_{n} \sup _{q \in \mathcal{F}} \psi\left(G\left(q, J x_{n}\right)\right)+\mu_{n}$ and for each $i=1,2, \ldots, m,\left\{r_{i, n}\right\} \subset[d, \infty)$ for some $d>0$. If, for each $j=1,2, \ldots, l, \liminf _{n \rightarrow \infty} \lambda_{j, n}>0, \lim _{n \rightarrow \infty} \alpha_{n}=0$ and $\liminf _{n \rightarrow \infty} \beta_{n}<1$, then the sequence $\left\{x_{n}\right\}$ converges strongly to a point $\Pi_{\mathcal{F}}^{f} x_{1}$.

Proof We split the proof into five steps.

Step 1. We first show that $C_{n}$ is closed and convex for all $n \geq 1$. From the definitions $C_{1}=C$ is closed and convex. Suppose that $C_{n}$ is closed and convex for all $n \geq 1$. For any $b \in C_{n}$, we know that $G\left(b, J y_{n}\right) \leq G\left(b, J x_{n}\right)+\zeta_{n}$ is equivalent to the following:

$$
\begin{aligned}
& 2 \alpha_{n}\left\langle b, J x_{1}\right\rangle+2\left(1-\alpha_{n}\right)\left\langle b, J x_{n}\right\rangle-2\left\langle b, J y_{n}\right\rangle \\
& \quad \leq \alpha_{n}\left\|x_{1}\right\|^{2}+\left(1-\alpha_{n}\right)\left\|x_{n}\right\|^{2}-\left\|y_{n}\right\|^{2}+\zeta_{n} .
\end{aligned}
$$

Therefore, $C_{n+1}$ is closed and convex for all $n \geq 1$.

Step 2. We show that $\mathcal{F} \subset C_{n}$ for all $n \geq 1$. Now, we show by induction that $\mathcal{F} \subset C_{n}$ for all $n \geq 1$. It is obvious that $\mathcal{F} \subset C_{1}=C$. Suppose that $\mathcal{F} \subset C_{n}$ for some $n \geq 1$. Define $u_{n}=$ $K_{n}^{m} z_{n}$, when $K_{n}^{i}=T_{r_{i, n}}^{\theta_{i}} T_{r_{i-1, n}}^{\theta_{i-1}} \ldots T_{r_{1, n}}^{\theta_{1}}$ for all $j=1,2, \ldots, m$ with $K_{n}^{0}=I$ and define $z_{n}=\Delta_{n}^{l} x_{n}$ 
when $\Delta_{n}^{j}:=J_{\lambda_{j, n}}^{A_{j}} \circ J_{\lambda_{j-1, n}}^{A_{j-1}} \circ \cdots \circ J_{\lambda_{1, n}}^{A_{1}}$ for all $j=1,2, \ldots, l$ with $\Delta_{n}^{0}=I$. Let $q \in \mathcal{F}$. Then we have

$$
\begin{aligned}
G\left(q, J u_{n}\right) & =G\left(q, J K_{n}^{m} z_{n}\right) \\
& \leq G\left(q, J z_{n}\right) \\
& =G\left(q, J\left(\Delta_{n}^{l} x_{n}\right)\right) \\
& \leq G\left(q, J x_{n}\right) .
\end{aligned}
$$

Since $S$ is a totally quasi- $\phi$-asymptotically nonexpansive mapping, from (10) we have

$$
\begin{aligned}
& G\left(q, J y_{n}\right) \\
&= G\left(q,\left(\alpha_{n} J x_{1}+\beta_{n} J S^{n} x_{n}+\gamma_{n} J u_{n}\right)\right) \\
&=\|q\|^{2}-2 \alpha_{n}\left\langle q, J x_{1}\right\rangle-2 \beta_{n}\left\langle q, J S^{n} x_{n}\right\rangle-2 \gamma_{n}\left\langle q, J u_{n}\right\rangle \\
&+\left\|\alpha_{n} J x_{1}+\beta_{n} J S^{n} x_{n}+\gamma_{n} J u_{n}\right\|^{2}+2 \rho f(q) \\
& \leq\|q\|^{2}-2 \alpha_{n}\left\langle q, J x_{1}\right\rangle-2 \beta_{n}\left\langle q, J S^{n} x_{n}\right\rangle-2 \gamma_{n}\left\langle q, J u_{n}\right\rangle \\
&+\alpha_{n}\left\|J x_{n}\right\|^{2}+\beta_{n}\left\|J S^{n} x_{n}\right\|^{2}+\gamma_{n}\left\|J u_{n}\right\|^{2}+2 \rho f(q) \\
&= \alpha_{n} G\left(q, J x_{1}\right)+\beta_{n} G\left(q, J S^{n} x_{n}\right)+\gamma_{n} G\left(q, J u_{n}\right) \\
& \leq \alpha_{n} G\left(q, J x_{1}\right)+\beta_{n}\left(G\left(q, J x_{n}\right)+v_{n} \psi\left(G\left(q, J x_{n}\right)\right)+\mu_{n}\right)+\gamma_{n} G\left(q, J u_{n}\right) \\
& \leq \alpha_{n} G\left(q, J x_{1}\right)+\beta_{n} G\left(q, J x_{n}\right)+\gamma_{n} G\left(q, J u_{n}\right)+\beta_{n}\left(v_{n} \psi\left(G\left(q, J x_{n}\right)\right)+\mu_{n}\right) \\
& \leq \alpha_{n} G\left(q, J x_{1}\right)+\beta_{n} G\left(q, J x_{n}\right)+\gamma_{n} G\left(q, J u_{n}\right)+v_{n} \sup _{q \in \mathcal{F}} \psi\left(G\left(q, J x_{n}\right)\right)+\mu_{n} \\
& \leq \alpha_{n} G\left(q, J x_{1}\right)+\beta_{n} G\left(q, J x_{n}\right)+\gamma_{n} G\left(q, J u_{n}\right)+\zeta_{n} \\
& \leq \alpha_{n} G\left(q, J x_{1}\right)+\beta_{n} G\left(q, J x_{n}\right)+\gamma_{n} G\left(q, J z_{n}\right)+\zeta_{n} \\
& \leq \alpha_{n} G\left(q, J x_{1}\right)+\beta_{n} G\left(q, J x_{n}\right)+\gamma_{n} G\left(q, J x_{n}\right)+\zeta_{n} \\
& \leq \alpha_{n} G\left(q, J x_{1}\right)+\left(\beta_{n}+\gamma_{n}\right) G\left(q, J x_{n}\right)+\zeta_{n} \\
&= \alpha_{n} G\left(q, J x_{1}\right)+\left(1-\alpha_{n}\right) G\left(q, J x_{n}\right)+\zeta_{n} .
\end{aligned}
$$

This shows that $q \in C_{n+1}$, which implies that $\mathcal{F} \subset C_{n+1}$ and so $\mathcal{F} \subset C_{n}$ for all $n \geq 1$ and the sequence $\left\{x_{n}\right\}$ is well defined.

Step 3. We show that $x_{n} \rightarrow p, y_{n} \rightarrow p, z_{n} \rightarrow p$ and $u_{n} \rightarrow p$ as $n \rightarrow \infty$. Since $f: E \rightarrow \mathbf{R}$ is a convex and lower semi-continuous function, from Lemma 4 , we known that there exist $x^{*} \in E^{*}$ and $\alpha \in \mathbf{R}$ such that

$$
f(x) \geq\left\langle x, x^{*}\right\rangle+\alpha
$$

for all $x \in E$. Since $x_{n} \in C_{n} \subset E$, it follows that

$$
\begin{aligned}
G\left(x_{n}, J x_{1}\right) & =\left\|x_{n}\right\|^{2}-2\left\langle x_{n}, J x_{1}\right\rangle+\left\|x_{1}\right\|^{2}+2 \rho f\left(x_{n}\right) \\
& \geq\left\|x_{n}\right\|^{2}-2\left\langle x_{n}, J x_{1}\right\rangle+\left\|x_{1}\right\|^{2}+2 \rho\left\langle x_{n}, x^{*}\right\rangle+2 \rho \alpha
\end{aligned}
$$




$$
\begin{aligned}
& =\left\|x_{n}\right\|^{2}-2\left\langle x_{n}, J x_{1}-\rho x^{*}\right\rangle+\left\|x_{1}\right\|^{2}+2 \rho \alpha \\
& \geq\left\|x_{n}\right\|^{2}-2\left\|x_{n}\right\|\left\|J x_{1}-\rho x^{*}\right\|+\left\|x_{1}\right\|^{2}+2 \rho \alpha \\
& =\left(\left\|x_{n}\right\|-\left\|J x_{1}-\rho x^{*}\right\|\right)^{2}+\left\|x_{1}\right\|^{2}-\left\|J x_{1}-\rho x^{*}\right\|^{2}+2 \rho \alpha .
\end{aligned}
$$

For all $q \in \mathcal{F}$ and $x_{n}=\Pi_{C_{n}}^{f} x_{1}$, we have

$$
G\left(q, J x_{1}\right) \geq G\left(x_{n}, J x_{1}\right) \geq\left(\left\|x_{n}\right\|-\left\|J x_{1}-\rho x^{*}\right\|\right)^{2}+\left\|x_{1}\right\|^{2}-\left\|J x_{1}-\rho x^{*}\right\|^{2}+2 \rho \alpha .
$$

That is, $\left\{x_{n}\right\}$ is bounded and so are $\left\{G\left(x_{n}, J x_{1}\right)\right\}$ and $\left\{y_{n}\right\}$. By using the fact that $x_{n+1}=$ $\Pi_{C_{n+1}}^{f} x_{1} \in C_{n+1} \subset C_{n}$ and $x_{n}=\Pi_{C_{n}}^{f} x_{1}$, it follows from Lemma 6 and (3) that

$$
0 \leq\left(\left\|x_{n+1}-\right\| x_{n} \|\right)^{2} \leq \phi\left(x_{n+1}, x_{n}\right) \leq G\left(x_{n+1}, J x_{1}\right)-G\left(x_{n}, J x_{1}\right) .
$$

This implies that $\left\{G\left(x_{n}, J x_{1}\right)\right\}$ is nondecreasing and so $\lim _{n \rightarrow \infty} G\left(x_{n}, J x_{1}\right)$ exists. Taking $n \rightarrow$ $\infty$, we obtain

$$
\lim _{n \rightarrow \infty} \phi\left(x_{n+1}, x_{n}\right)=0 .
$$

Since $\left\{x_{n}\right\}$ is bounded, $E$ is reflexive and $C_{n}$ is closed and convex for all $n \geq 1$. We can assume that $x_{n} \rightarrow p \in C_{n}$ as $n \rightarrow \infty$. From the fact that $x_{n}=\Pi_{C_{n}}^{f} x_{1}$, we get

$$
G\left(x_{n}, J x_{1}\right) \leq G\left(p, J x_{1}\right)
$$

for all $n \geq 1$. Since $f$ is convex and lower semi-continuous, we have

$$
\begin{aligned}
\liminf _{n \rightarrow \infty} G\left(x_{n}, J x_{1}\right) & =\liminf _{n \rightarrow \infty}\left\{\left\|x_{n}\right\|^{2}-2\left\langle x_{n}, J x_{1}\right\rangle+\left\|x_{1}\right\|^{2}+2 \rho f\left(x_{n}\right)\right\} \\
& \geq\|p\|^{2}-2\left\langle p, J x_{1}\right\rangle+\left\|x_{1}\right\|^{2}+2 \rho f(p) \\
& =G\left(x_{n}, J x_{1}\right) .
\end{aligned}
$$

By (15) and (16), we get

$$
G\left(p, J x_{1}\right) \leq \liminf _{n \rightarrow \infty} G\left(x_{n}, J x_{1}\right) \leq \limsup _{n \rightarrow \infty} G\left(x_{n}, J x_{1}\right) \leq G\left(p, J x_{1}\right) .
$$

That is, $\lim _{n \rightarrow \infty} G\left(x_{n}, J x_{1}\right)=G\left(p, J x_{1}\right)$, which implies that $\left\|x_{n}\right\| \rightarrow\|p\|$ as $n \rightarrow \infty$. Since $E$ has the Kadec-Klee property, we obtain

$$
\lim _{n \rightarrow \infty} x_{n}=p
$$

We also have

$$
\lim _{n \rightarrow \infty} x_{n+1}=p
$$

From (17), we get

$$
\lim _{n \rightarrow \infty} \zeta_{n}=\lim _{n \rightarrow \infty}\left(v_{n} \sup _{q \in \mathcal{F}} \psi\left(G\left(q, J x_{n}\right)\right)+\mu_{n}\right)=0 .
$$


From (17) and (18), we have $\lim _{n \rightarrow \infty}\left\|x_{n}-x_{n+1}\right\|=0$. Since $J$ is uniformly norm-to-norm continuous, it follows that

$$
\lim _{n \rightarrow \infty}\left\|J x_{n}-J x_{n+1}\right\|=0 .
$$

Moreover, since $x_{n+1}=\Pi_{C_{n+1}}^{f} x_{1} \in C_{n+1} \subset C_{n}$ and (9), we have

$$
G\left(x_{n+1}, J y_{n}\right) \leq \alpha_{n} G\left(x_{n+1}, J x_{1}\right)+\left(1-\alpha_{n}\right) G\left(x_{n+1}, J x_{n}\right)+\zeta_{n}
$$

is equivalent to the following:

$$
\phi\left(x_{n+1}, y_{n}\right) \leq \alpha_{n} \phi\left(x_{n+1}, x_{1}\right)+\left(1-\alpha_{n}\right) \phi\left(x_{n+1}, x_{n}\right)+\zeta_{n} .
$$

Since $\lim _{n \rightarrow \infty} \alpha_{n}=0$, (14) and (19), we have

$$
\lim _{n \rightarrow \infty} \phi\left(x_{n+1}, y_{n}\right)=0 .
$$

By (3), it follows that

$$
\left\|y_{n}\right\| \rightarrow\|p\|
$$

as $n \rightarrow \infty$. Since $J$ is uniformly norm-to-norm continuous, we obtain

$$
\left\|J y_{n}\right\| \rightarrow\|J p\|
$$

as $n \rightarrow \infty$. This implies that $\left\{\left\|y_{n}\right\|\right\}$ is bounded in $E^{*}$, Since $E^{*}$ is reflexive, we assume that $J y_{n} \rightarrow y^{\prime \prime} \in E^{*}$ as $n \rightarrow \infty$. In view of $J(E)=E^{*}$, there exists $y \in E$ such that $J y=y^{*}$. It follows that

$$
\begin{aligned}
\phi\left(x_{n+1}, y_{n}\right) & =\left\|x_{n+1}\right\|^{2}-2\left\langle x_{n+1}, J y_{n}\right\rangle+\left\|y_{n}\right\|^{2} \\
& =\left\|x_{n+1}\right\|^{2}-2\left\langle x_{n+1}, J y_{n}\right\rangle+\left\|J y_{n}\right\|^{2} .
\end{aligned}
$$

Taking $\liminf _{n \rightarrow \infty}$ on both sides of the equality above, since $\|\cdot\|$ is weak lower semicontinuous, this yields that

$$
\begin{aligned}
0 & \geq\|p\|^{2}-2\left\langle p, y^{*}\right\rangle+\left\|y^{*}\right\|^{2} \\
& =\|p\|^{2}-2\langle p, J y\rangle+\|J y\|^{2} \\
& =\|p\|^{2}-2\langle p, J y\rangle+\|y\|^{2} \\
& =\phi(p, y) .
\end{aligned}
$$

From Remark 2, $p=y$, which implies that $y^{*}=J p$. It follows that $J y_{n} \rightarrow J p \in E^{*}$ as $n \rightarrow \infty$. From (24) and the Kadec-Klee property of $E^{*}$, we have $J y_{n} \rightarrow J p$ as $n \rightarrow \infty$. Note that $J^{-1}: E^{*} \rightarrow E$ is norm-weak"-continuous, that is, $y_{n_{i}} \rightarrow p$ as $n \rightarrow \infty$. From (23) and the Kadec-Klee property of $E$, we have

$$
\lim _{n \rightarrow \infty} y_{n}=p
$$


From (11), we have

$$
\begin{aligned}
G\left(q, J y_{n}\right) & \leq \alpha_{n} G\left(q, J x_{1}\right)+\beta_{n} G\left(q, J x_{n}\right)+\gamma_{n} G\left(q, J z_{n}\right)+\zeta_{n} \\
& \leq \alpha_{n} G\left(q, J x_{1}\right)+\left(1-\alpha_{n}\right) G\left(q, J x_{n}\right)+\zeta_{n} .
\end{aligned}
$$

From (17), (19), (27) and the conditions $\lim _{n \rightarrow \infty} \alpha_{n}=0, \liminf _{n \rightarrow \infty} \beta_{n}<1$, it follows that for any $q \in F, \lim _{n \rightarrow \infty} \phi\left(q, z_{n}\right)=\phi(q, p)$. Let $z_{n}=\Delta_{n}^{l} x_{n}$ for all $n \geq 1$. From Lemma 11(1), it follows that for any $q \in F$,

$$
\begin{aligned}
\phi\left(z_{n}, x_{n}\right) & =\phi\left(\Delta_{n}^{l} x_{n}, x_{n}\right) \\
& \leq \phi\left(q, x_{n}\right)-\phi\left(q, \Delta_{n}^{l} x_{n}\right) \\
& =\phi\left(q, x_{n}\right)-\phi\left(q, z_{n}\right) .
\end{aligned}
$$

Taking $n \rightarrow \infty$ on both sides of the inequality above, we have

$$
\lim _{n \rightarrow \infty} \phi\left(z_{n}, x_{n}\right)=0
$$

From (3), it follows that $\left(\left\|x_{n}\right\|-\left\|z_{n}\right\|\right)^{2} \rightarrow 0$ as $n \rightarrow \infty$. Since $\left\|x_{n}\right\| \rightarrow\|p\|$ as $n \rightarrow \infty$, we have

$$
\left\|z_{n}\right\| \rightarrow\|p\|
$$

as $n \rightarrow \infty$. Since $J$ is uniformly norm-to-norm continuous on bounded subsets of $E$, it follows that

$$
\left\|J z_{n}\right\| \rightarrow\|J p\|
$$

as $n \rightarrow \infty$. This implies that $\left\{\left\|J z_{n}\right\|\right\}$ is bounded in $E^{*}$. Since $E^{*}$ is reflexive, we can assume that $J z_{n} \rightarrow z^{*} \in E^{*}$ as $n \rightarrow \infty$. In view of $J(E)=E^{*}$, there exists $z \in E$ such that $J z=z^{*}$, and so

$$
\begin{aligned}
\phi\left(x_{n}, z_{n}\right) & =\left\|x_{n}\right\|^{2}-2\left\langle x_{n}, J z_{n}\right\rangle+\left\|z_{n}\right\|^{2} \\
& =\left\|x_{n}\right\|^{2}-2\left\langle x_{n}, J z_{n}\right\rangle+\left\|J z_{n}\right\|^{2} .
\end{aligned}
$$

Taking $\liminf _{n \rightarrow \infty}$ on both sides of the equality above, from the weak lower semicontinuity of the norm $\|\cdot\|$, it follows that

$$
\begin{aligned}
0 & \geq\|p\|^{2}-2\left\langle p, z^{*}\right\rangle+\left\|z^{*}\right\|^{2} \\
& =\|p\|^{2}-2\langle p, J z\rangle+\|J z\|^{2} \\
& =\|p\|^{2}-2\langle p, J z\rangle+\|z\|^{2} \\
& =\phi(p, z) .
\end{aligned}
$$

From Remark 2, we have $p=z$, which implies that $z^{*}=J p$ and so $J z_{n} \rightarrow J p \in E^{*}$ as $n \rightarrow \infty$. From (29) and the Kadec-Klee property of $E^{*}$, we have $J z_{n} \rightarrow J p$ as $n \rightarrow \infty$. Since $J^{-1}$ is 
norm-weak"-continuous, that is, $z_{n} \rightarrow p$, from (28) and the Kadec-Klee property of $E$, it follows that

$$
\lim _{n \rightarrow \infty} z_{n}=p
$$

From (11), we have

$$
\begin{aligned}
G\left(q, J y_{n}\right) & \leq \alpha_{n} G\left(q, J x_{1}\right)+\beta_{n} G\left(q, J x_{n}\right)+\gamma_{n} G\left(q, J u_{n}\right)+\zeta_{n} \\
& \leq \alpha_{n} G\left(q, J x_{1}\right)+\left(1-\alpha_{n}\right) G\left(q, J x_{n}\right)+\zeta_{n} .
\end{aligned}
$$

From (17), (19), (27) and the conditions $\lim _{n \rightarrow \infty} \alpha_{n}=0, \liminf _{n \rightarrow \infty} \beta_{n}<1$, it follows that $\lim _{n \rightarrow \infty} \phi\left(q, u_{n}\right)=\phi(q, p)$. From Lemma 9, it follows that for any $q \in F$ and $u_{n}=K_{n}^{m} z_{n}$,

$$
\begin{aligned}
\phi\left(u_{n}, x_{n}\right) & =\phi\left(K_{n}^{m} z_{n}, x_{n}\right) \\
& \leq \phi\left(q, z_{n}\right)-\phi\left(q, K_{n}^{m} x_{n}\right) \\
& =\phi\left(q, z_{n}\right)-\phi\left(q, u_{n}\right) .
\end{aligned}
$$

Taking $n \rightarrow \infty$ on both sides of the inequality above, we have

$$
\lim _{n \rightarrow \infty} \phi\left(x_{n}, u_{n}\right)=0
$$

From (3), we have

$$
\left(\left\|x_{n}\right\|-\left\|u_{n}\right\|\right)^{2} \rightarrow 0
$$

as $n \rightarrow \infty$. Since $\left\|x_{n}\right\| \rightarrow\|p\|$, we have

$$
\left\|u_{n}\right\| \rightarrow\|p\|
$$

as $n \rightarrow \infty$, and so

$$
\left\|J u_{n}\right\| \rightarrow\|J p\|
$$

as $n \rightarrow \infty$. That is, $\left\{\left\|J u_{n}\right\|\right\}$ is bounded in $E^{*}$. Since $E^{*}$ is reflexive, we can assume that $J u_{n} \rightarrow u^{*} \in E^{*}$ as $n \rightarrow \infty$. In view of $J(E)=E^{*}$, there exists $u \in E$ such that $J u=u^{*}$. It follows that

$$
\begin{aligned}
\phi\left(x_{n+1}, u_{n}\right) & =\left\|x_{n+1}\right\|^{2}-2\left\langle x_{n+1}, J u_{n}\right\rangle+\left\|u_{n}\right\|^{2} \\
& =\left\|x_{n+1}\right\|^{2}-2\left\langle x_{n+1}, J u_{n}\right\rangle+\left\|J u_{n}\right\|^{2} .
\end{aligned}
$$

Taking $\liminf _{n \rightarrow \infty}$ on both sides of the equality above, since $\|\cdot\|$ is weak lower semicontinuous, it follows that

$$
\begin{aligned}
0 & \geq\|p\|^{2}-2\left\langle p, u^{*}\right\rangle+\left\|u^{*}\right\|^{2} \\
& =\|p\|^{2}-2\langle p, J u\rangle+\|J u\|^{2}
\end{aligned}
$$




$$
\begin{aligned}
& =\|p\|^{2}-2\langle p, J u\rangle+\|u\|^{2} \\
& =\phi(p, u) .
\end{aligned}
$$

From Remark 2, $p=u$, that is, $u^{*}=J p$. It follows that $J u_{n} \rightarrow J p \in E^{*}$. From (36) and the Kadec-Klee property of $E^{*}$, we have $J u_{n} \rightarrow J p$ as $n \rightarrow \infty$. Since $J^{-1}$ is norm-weak"continuous, that is, $u_{n} \rightarrow p$ as $n \rightarrow \infty$. From (35) and the Kadec-Klee property of $E$, we have

$$
\lim _{n \rightarrow \infty} u_{n}=p
$$

Step 4. We show that $p \in \mathcal{F}=F(S) \cap\left(\bigcap_{i=1}^{m} \operatorname{EP}\left(\theta_{i}\right)\right) \cap\left(\bigcap_{j=1}^{l} A_{j}^{-1} 0\right)$. First, we show that $p \in \bigcap_{j=1}^{l} A_{j}^{-1} 0$. Let $z_{n}=\Delta_{n}^{l} x_{n}$ for each $n \geq 1$. Then, for any $q \in F$, it follows that for each $j=1,2, \ldots, l$,

$$
\begin{aligned}
\phi\left(q, z_{n}\right) & =\phi\left(q, \Delta_{n}^{l} x_{n}\right) \\
& \leq \phi\left(q, \Delta_{n}^{l-1} x_{n}\right) \\
& \leq \phi\left(q, \Delta_{n}^{l-2} x_{n}\right) \\
& \ldots \\
& \leq \phi\left(q, \Delta_{n}^{j} x_{n}\right) .
\end{aligned}
$$

By Lemma 11, for each $j=1,2, \ldots, m$, we have

$$
\begin{aligned}
\phi\left(\Delta_{n}^{j} x_{n}, x_{n}\right) & \leq \phi\left(q, x_{n}\right)-\phi\left(q, \Delta_{n}^{j} x_{n}\right) \\
& \leq \phi\left(q, x_{n}\right)-\phi\left(q, z_{n}\right) .
\end{aligned}
$$

Since $x_{n} \rightarrow p$ and $z_{n} \rightarrow p$ as $n \rightarrow \infty$, we get $\phi\left(\Delta_{n}^{j} x_{n}, x_{n}\right) \rightarrow 0$ as $n \rightarrow \infty$ for all $j=1,2, \ldots, m$. From (3), it follows that

$$
\left(\left\|\Delta_{n}^{j} x_{n}\right\|-\left\|x_{n}\right\|\right)^{2} \rightarrow 0
$$

as $n \rightarrow \infty$ for all $j=1,2, \ldots, m$. Since $\left\|x_{n}\right\| \rightarrow\|p\|$ as $n \rightarrow \infty$, we also have

$$
\left\|\Delta_{n}^{j} x_{n}\right\| \rightarrow\|p\|
$$

as $n \rightarrow \infty$ for all $j=1,2, \ldots, m$. This implies that for each $j=1,2, \ldots, m,\left\{\Delta_{n}^{j} x_{n}\right\}$ is bounded. Since $E$ is reflexive, without loss of generality, we can assume that $\Delta_{n}^{j} x_{n} \rightarrow k$ as $n \rightarrow \infty$. Since $C_{n}$ is closed and convex for each $n \geq 1$, it is obvious that $k \in C_{n}$. Again, since

$$
\phi\left(\Delta_{n}^{j} x_{n}, x_{n}\right)=\left\|\Delta_{n}^{j} x_{n}\right\|^{2}-2\left\langle\Delta_{n}^{j} x_{n}, J x_{n}\right\rangle+\left\|x_{n}\right\|^{2},
$$

taking $\liminf f_{n \rightarrow \infty}$ on both sides of the equality above, we have

$$
0 \geq\|k\|^{2}-2\langle k, J p\rangle+\|p\|^{2}=\phi(k, p) .
$$


That is, $k=p$ and it follows that for all $j=1,2, \ldots, l$,

$$
\Delta_{n}^{j} x_{n} \rightarrow p
$$

as $n \rightarrow \infty$. Thus, from (42), (44) and the Kadec-Klee property, it follows that

$$
\lim _{n \rightarrow \infty} \Delta_{n}^{j} x_{n}=p
$$

for all $j=1,2, \ldots, m$. We also have

$$
\lim _{n \rightarrow \infty} \Delta_{n}^{j-1} x_{n}=p
$$

for all $j=1,2, \ldots, m$, and so

$$
\lim _{n \rightarrow \infty}\left\|\Delta_{n}^{j} x_{n}-\Delta_{n}^{j-1} x_{n}\right\|=0
$$

for all $j=1,2, \ldots, m$. Since $J$ is uniformly norm-to-norm continuous on bounded subsets of $E$ and $\liminf _{n \rightarrow \infty} \lambda_{j, n}>0$ for each $j=1,2, \ldots, l$, we have

$$
\lim _{n \rightarrow \infty} \frac{1}{\lambda_{j, n}}\left\|J \Delta_{n}^{j} x_{n}-J \Delta_{n}^{j-1} x_{n}\right\|=0 .
$$

Let $\Delta_{n}^{j} x_{n}=J_{\lambda_{j, n}}^{j} \Delta_{n}^{j-1} x_{n}$ for each $j=1,2, \ldots, l$. Then we have

$$
\lim _{n \rightarrow \infty}\left\|A_{\lambda_{j, n}} \Delta_{n}^{j-1} x_{n}\right\|=\lim _{n \rightarrow \infty} \frac{1}{\lambda_{j, n}}\left\|J \Delta_{n}^{j} x_{n}-J \Delta_{n}^{j-1} x_{n}\right\|=0 .
$$

For any $\left(w, w^{*}\right) \in G\left(A_{j}\right)$ and $\left(\Delta_{n}^{j} x_{n}, A_{\lambda_{j, n}} \Delta_{n}^{j-1} x_{n}\right) \in G\left(A_{j}\right)$ for each $j=1,2, \ldots, l$, it follows from the monotonicity of $A_{j}$ that for all $n \geq 1$,

$$
\left\langle w-\Delta_{n}^{j} x_{n}, w^{*}-A_{\lambda_{j, n}} \Delta_{n}^{j-1} x_{n}\right\rangle \geq 0
$$

for all $j=1,2, \ldots, l$. Letting $n \rightarrow \infty$ in the inequality above, we get $\left\langle w-p, w^{*}\right\rangle \geq 0$ for all $j=1,2, \ldots, l$. Since $A_{j}$ is maximal monotone for all $j=1,2, \ldots, l$, we obtain $p \in \bigcap_{j=1}^{l} A_{j}^{-1} 0$.

Next, we show that $p \in \bigcap_{i=1}^{m} \mathrm{EP}\left(\theta_{i}\right)$. For any $q \in F$ and $u_{n}=K_{n}^{m} z_{n}$, we observe that

$$
\begin{aligned}
\phi\left(q, u_{n}\right) & =\phi\left(q, K_{n}^{m} z_{n}\right) \\
& \leq \phi\left(q, K_{n}^{m-1} z_{n}\right) \\
& \leq \phi\left(q, K_{n}^{m-2} z_{n}\right) \\
& \ldots \\
& \leq \phi\left(q, K_{n}^{i} z_{n}\right) .
\end{aligned}
$$

By Lemma 10 , for $i=1,2, \ldots, m$, we have

$$
\begin{aligned}
\phi\left(K_{n}^{i} z_{n}, x_{n}\right) & \leq \phi\left(q, x_{n}\right)-\phi\left(q, K_{n}^{i} z_{n}\right) \\
& \leq \phi\left(q, x_{n}\right)-\phi\left(q, u_{n}\right) .
\end{aligned}
$$


Since $x_{n} \rightarrow p$ and $u_{n} \rightarrow p$ as $n \rightarrow \infty$, we get $\phi\left(K_{n}^{i} z_{n}, x_{n}\right) \rightarrow 0$ as $n \rightarrow \infty$ for all $i=1,2, \ldots, m$. From (3), it follows that

$$
\left(\left\|K_{n}^{i} z_{n}\right\|-\left\|x_{n}\right\|\right)^{2} \rightarrow 0
$$

as $n \rightarrow \infty$. Since $\left\|x_{n}\right\| \rightarrow\|p\|$ as $n \rightarrow \infty$, we also have

$$
\left\|K_{n}^{i} z_{n}\right\| \rightarrow\|p\|
$$

as $n \rightarrow \infty$. Since $\left\{K_{n}^{i} z_{n}\right\}$ is bounded and $E$ is reflexive, without loss of generality, we assume that $K_{n}^{i} z_{n} \rightarrow h$ as $n \rightarrow \infty$. Since $C_{n}$ is closed and convex for each $n \geq 1$, it is obvious that $h \in C_{n}$. Again, since

$$
\phi\left(K_{n}^{i} z_{n}, x_{n}\right)=\left\|K_{n}^{i} z_{n}\right\|^{2}-2\left\langle K_{n}^{i} z_{n}, J x_{n}\right\rangle+\left\|x_{n}\right\|^{2}
$$

taking $\lim \inf _{n \rightarrow \infty}$ on both sides of the equality above, we have

$$
0 \geq\|h\|^{2}-2\langle h, J p\rangle+\|p\|^{2}=\phi(h, p) .
$$

That is, $h=p$ and it follows that for all $i=1,2, \ldots, m$, it follows that

$$
K_{n}^{i} z_{n} \rightarrow p
$$

as $n \rightarrow \infty$. Thus, from (52), (54) and the Kadec-Klee property, it follows that

$$
\lim _{n \rightarrow \infty} K_{n}^{i} z_{n}=p
$$

for all $i=1,2, \ldots, m$. We also have

$$
\lim _{n \rightarrow \infty} K_{n}^{i-1} z_{n}=p
$$

for all $i=1,2, \ldots, m$, and so

$$
\left\|K_{n}^{i} z_{n}-K_{n}^{i-1} z_{n}\right\|=0
$$

for all $i=1,2, \ldots, m$. Since $J$ is uniformly norm-to-norm continuous, we obtain

$$
\lim _{n \rightarrow \infty}\left\|J K_{n}^{i} z_{n}-J K_{n}^{i-1} z_{n}\right\|=0
$$

for all $i=1,2, \ldots, m$. From $r_{i, n}>0$ for all $i=1,2, \ldots, m$, we have

$$
\frac{\left\|J K_{n}^{i} z_{n}-J K_{n}^{i-1} z_{n}\right\|}{r_{i, n}} \rightarrow 0
$$

as $n \rightarrow \infty$ and

$$
\theta_{i}\left(K_{n}^{i} z_{n}, y\right)+\frac{1}{r_{i, n}}\left\langle y-K_{n}^{i} z_{n}, J K_{n}^{i} z_{n}-J K_{n}^{i-1} z_{n}\right\rangle \geq 0
$$


for all $y \in C$. Thus, by (A2), we have

$$
\begin{aligned}
\left\|y-K_{n}^{i} z_{n}\right\| \frac{\left\|J K_{n}^{i} z_{n}-J K_{n}^{i-1} z_{n}\right\|}{r_{i, n}} & \geq \frac{1}{r_{i, n}}\left\langle y-K_{n}^{i} z_{n}, J K_{n}^{i} z_{n}-J K_{n}^{i-1} z_{n}\right\rangle \\
& \geq-\theta_{i}\left(K_{n}^{i} z_{n}, y\right) \\
& \geq \theta_{i}\left(y, K_{n}^{i} z_{n}\right)
\end{aligned}
$$

for all $y \in C$ and $K_{n}^{i} z_{n} \rightarrow p$ as $n \rightarrow \infty$, and so $\theta_{i}(y, p) \leq 0$ for all $y \in C$. For any $t$ with $0<t<$ 1 , define $y_{t}=t y+(1-t) p$. Then $y_{t} \in C$, which implies that $\theta_{i}\left(y_{t}, p\right) \leq 0$ for all $i=1,2, \ldots, m$. Thus, from (A1), it follows that

$$
0=\theta_{i}\left(y_{t}, y_{t}\right) \leq t \theta_{i}\left(y_{t}, y\right)+(1-t) \theta_{i}\left(y_{t}, p\right) \leq t \theta_{i}\left(y_{t}, y\right)
$$

and so $\theta_{i}\left(y_{t}, y\right) \geq 0$ for all $i=1,2, \ldots, m$. From (A3), we have $\theta_{i}(p, y) \geq 0$ for all $y \in C$ and $i=1,2, \ldots, m$, that is, $p \in \operatorname{EP}\left(\theta_{i}\right)$ for all $i=1,2, \ldots, m$. This implies that $p \in \bigcap_{i=1}^{m} \operatorname{EP}\left(\theta_{i}\right)$.

Finally, we show that $p \in F(S)$. Since $\left\{x_{n}\right\}$ is bounded, the mapping $S$ is also bounded. From $y_{n} \rightarrow p$ as $n \rightarrow \infty$ and (9), we have

$$
\left\|J S^{n} x_{n}\right\| \rightarrow\|J p\|
$$

as $n \rightarrow \infty$. Since $J^{-1}: E^{\prime \prime} \rightarrow E$ is norm-weak"-continuous,

$$
S^{n} x_{n} \rightarrow p
$$

as $n \rightarrow \infty$.

On the other hand, in view of (59), it follows that

$$
\left|\left\|S^{n} x_{n}\right\|-\|p\|\right|=\left|\left\|J\left(S^{n} x_{n}\right)\right\|-\|J p\|\right| \leq\left\|J\left(S^{n} x_{n}\right)-J p\right\|=0
$$

and so $\left\|S^{n} x_{n}\right\| \rightarrow\|p\|$. Since $E$ has the Kadee-Klee property, we get

$$
S^{n} x_{n} \rightarrow p
$$

for all $n \geq 1$. By using the triangle inequality, since $S$ is uniformly $L$-Lipschitz continuous, we get

$$
\begin{aligned}
& \left\|S^{n+1} x_{n}-S^{n} x_{n}\right\| \\
& \quad \leq\left\|S^{n+1} x_{n}-S^{n+1} x_{n+1}\right\|+\left\|S^{n+1} x_{n+1}-x_{n+1}\right\|+\left\|x_{n+1}-x_{n}\right\|+\left\|x_{n}-S^{n} x_{n}\right\| \\
& \quad \leq(L+1)\left\|x_{n+1}-x_{n}\right\|+\left\|S^{n+1} x_{n+1}-x_{n+1}\right\|+\left\|x_{n}-S^{n} x_{n}\right\| .
\end{aligned}
$$

Since $S^{n} x_{n} \rightarrow p$ as $n \rightarrow \infty$, we get $S^{n+1} x_{n} \rightarrow p$ as $n \rightarrow \infty$, and so $S S^{n} x_{n} \rightarrow p$ as $n \rightarrow \infty$. In view of the closedness of $S$, we have $S p=p$, which implies that $p \in F(S)$. Hence $p \in \mathcal{F}$.

Step 5. We show that $p=\Pi_{\mathcal{F}}^{f} x_{1}$. Since $\mathcal{F}$ is a closed and convex set, it follows from Lemma 5 that $\Pi_{\mathcal{F}}^{f} x_{1}$ is single-valued, which is denoted by $\hat{p}$. By the definitions of $x_{n}=$ 
$\Pi_{C_{n}}^{f} x_{1}$ and $\hat{p} \in \mathcal{F} \subset C_{n}$, we also have

$$
G\left(x_{n}, J x_{1}\right) \leq G\left(\hat{p}, J x_{1}\right)
$$

for all $n \geq 1$. By the definitions of $G$ and $f$, we know that for any $x \in E, G(\xi, J x)$ is convex and lower semicontinuous with respect to $\xi$, and so

$$
G\left(p, J x_{1}\right) \leq \liminf _{n \rightarrow \infty} G\left(x_{n}, J x_{1}\right) \leq \limsup _{n \rightarrow \infty} G\left(x_{n}, J x_{1}\right) \leq G\left(\hat{p}, J x_{1}\right)
$$

From the definition of $\Pi_{\mathcal{F}}^{f} x_{1}$, since $p \in \mathcal{F}$, we conclude that $\hat{p}=p=\Pi_{\mathcal{F}}^{f} x_{1}$ and $x_{n} \rightarrow p$ as $n \rightarrow \infty$. This completes the proof.

Setting $v_{n}=\left(k_{n}-1\right), \mu_{n}=0$ and $\psi: \mathbf{R}^{+} \rightarrow 1$ in Theorem 1 , we have the following result.

Corollary 1 Let $C$ be a nonempty closed and convex subset of a uniformly smooth and strictly convex Banach space $E$ with the Kadec-Klee property. For each $i=1,2, \ldots, m$, let $\theta_{i}$ be a bifunction from $C \times C$ to $\mathbf{R}$ satisfying the conditions (A1)-(A4). Let $A_{j} \subset E \times E^{*}$ be a maximal monotone operator satisfying $D(A) \subset C$ and $J_{\lambda_{j, n}}^{A_{j}}=\left(J+\lambda_{j, n} A_{j}\right)^{-1} J$ for all $\lambda_{j, n}>0$ and $j=1,2, \ldots$, l. Let $S: C \rightarrow C$ be a closed and quasi- $\phi$-asymptotically nonexpansive mapping. Let $f: E \rightarrow \mathbf{R}^{+}$be a convex and lower semicontinuous function with $C \subset \operatorname{int}(D(f))$ and $f(0)=0$. Assume that $S$ is uniformly L-Lipschitz continuous and $\mathcal{F}=F(S) \cap\left(\bigcap_{i=1}^{m} \operatorname{EP}\left(\theta_{i}\right)\right) \cap$ $\left(\bigcap_{j=1}^{l} A_{j}^{-1} 0\right) \neq \emptyset$. For an initial point $x_{1} \in E$, define $C_{1}=C$ and the sequence $\left\{x_{n}\right\}$ in $C$ by

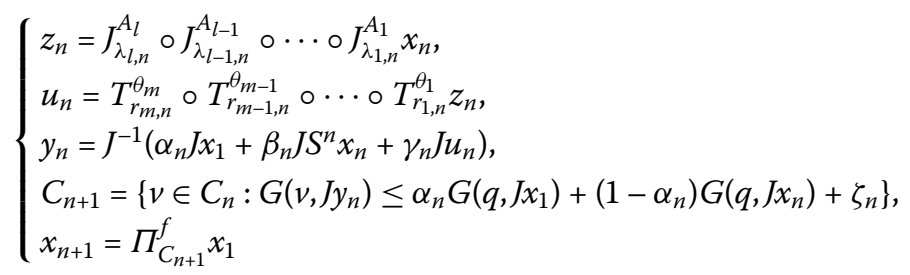

for all $n \geq 1$, where $\left\{\alpha_{n}\right\},\left\{\beta_{n}\right\}$ and $\left\{\gamma_{n}\right\}$ are the sequences in $(0,1)$ with $\alpha_{n}+\beta_{n}+\gamma_{n}=1$, $\zeta_{n}=\sup _{q \in \mathcal{F}}\left(k_{n}-1\right) G\left(q, J x_{n}\right)$ and, for each $i=1,2,3, \ldots, m,\left\{r_{i, n}\right\} \subset[d, \infty)$ for some $d>0$. If $\lim _{n \rightarrow \infty} \alpha_{n}=0, \liminf _{n \rightarrow \infty} \beta_{n}<1$ and $\liminf _{n \rightarrow \infty} \lambda_{j, n}>0$ for all $j=1,2, \ldots, l$, then the sequence $\left\{x_{n}\right\}$ converges strongly to a point $\Pi_{\mathcal{F}}^{f} x_{1}$.

If $f(x)=0$ for all $x \in E$ in Theorem 1 , then $G(x, J y)=\phi(x, y)$ and $\Pi_{\mathcal{F}}^{f}=\Pi_{\mathcal{F}}$ and so we have the following corollary.

Corollary 2 Let $C$ be a nonempty closed and convex subset of a uniformly smooth and strictly convex Banach space $E$ with the Kadec-Klee property. For each $i=1,2, \ldots, m$, let $\theta_{i}$ be a bifunction from $C \times C$ to $\mathbf{R}$ satisfying the conditions (A1)-(A4). Let $A_{j} \subset E \times E^{*}$ be a maximal monotone operator satisfying $D\left(A_{j}\right) \subset C$ and $J_{\lambda_{j, n}}^{A_{j}}=\left(J+\lambda_{j, n} A_{j}\right)^{-1} J$ for all $\lambda_{j, n}>0$ and $j=$ $1,2, \ldots$, l. Let $S: C \rightarrow C$ be a closed and totally quasi- $\phi$-asymptotically nonexpansive mapping with nonnegative real sequences $\left\{v_{n}\right\},\left\{\mu_{n}\right\}$ with $v_{n} \rightarrow 0, \mu_{n} \rightarrow 0$ as $n \rightarrow \infty$, respectively, and a strictly increasing continuous function $\psi: \mathbf{R}^{+} \rightarrow \mathbf{R}^{+}$with $\psi(0)=0$. Assume that $S$ is uniformly L-Lipschitz continuous and $\mathcal{F}=F(S) \cap\left(\bigcap_{i=1}^{m} \operatorname{EP}\left(\theta_{i}\right)\right) \cap\left(\bigcap_{j=1}^{l} A_{j}^{-1} 0\right) \neq \emptyset$. 
For an initial point $x_{1} \in E$, define $C_{1}=C$ and the sequence $\left\{x_{n}\right\}$ in $C$ by

$$
\left\{\begin{array}{l}
z_{n}=J_{\lambda_{l, n}}^{A_{l}} \circ J_{\lambda_{l-1, n}}^{A_{l-1}} \circ \cdots \circ J_{\lambda_{1, n}}^{A_{1}} x_{n}, \\
u_{n}=T_{r_{m, n}}^{\theta_{m}} \circ T_{r_{m-1, n}}^{\theta_{m-1}} \circ \cdots \circ T_{r_{1, n}}^{\theta_{1}} z_{n}, \\
y_{n}=J^{-1}\left(\alpha_{n} J x_{1}+\beta_{n} J S^{n} x_{n}+\gamma_{n} J u_{n}\right), \\
C_{n+1}=\left\{v \in C_{n}: \phi\left(v, y_{n}\right) \leq \alpha_{n} \phi\left(v, x_{1}\right)+\left(1-\alpha_{n}\right) \phi\left(v, x_{n}\right)+\zeta_{n}\right\}, \\
x_{n+1}=\Pi_{C_{n+1}} x_{1}
\end{array}\right.
$$

for all $n \geq 1$, where $\left\{\alpha_{n}\right\},\left\{\beta_{n}\right\}$ and $\left\{\gamma_{n}\right\}$ are the sequences in $(0,1)$ with $\alpha_{n}+\beta_{n}+\gamma_{n}=1$, $\zeta_{n}=v_{n} \sup _{q \in \mathcal{F}} \psi\left(\phi\left(q, x_{n}\right)\right)+\mu_{n}$ and, for each $i=1,2,3, \ldots, m,\left\{r_{i, n}\right\} \subset[d, \infty)$ for some $d>0$. If $\lim _{n \rightarrow \infty} \alpha_{n}=0, \liminf _{n \rightarrow \infty} \beta_{n}<1$ and $\liminf _{n \rightarrow \infty} \lambda_{j, n}>0$ for each $j=1,2, \ldots, l$, then the sequence $\left\{x_{n}\right\}$ converges strongly to a point $\Pi_{\mathcal{F}} x_{1}$.

Setting $v_{n}=\left(k_{n}-1\right), \mu_{n}=0$ and $\psi(x)=x$ in Theorem 1, we have the following corollary.

Corollary 3 Let $C$ be a nonempty closed and convex subset of a uniformly smooth and strictly convex Banach space $E$ with the Kadec-Klee property. For each $i=1,2, \ldots, m$, let $\theta_{i}$ be a bifunction from $C \times C$ to $\mathbf{R}$ satisfying the conditions (A1)-(A4). Let $A_{j} \subset E \times E^{*}$ be a maximal monotone operator satisfying $D(A) \subset C$ and $J_{\lambda_{j, n}}^{A_{j}}=\left(J+\lambda_{j, n} A_{j}\right)^{-1} J$ for all $\lambda_{j, n}>$ 0 and $j=1,2, \ldots, l$. Let $S: C \rightarrow C$ be a closed and quasi- $\phi$-asymptotically nonexpansive mapping. Assume that $S$ uniformly L-Lipschitz continuous and $\mathcal{F}=F(S) \cap\left(\bigcap_{i=1}^{m} \operatorname{EP}\left(\theta_{i}\right)\right) \cap$ $\left(\bigcap_{j=1}^{l} A_{j}^{-1} 0\right) \neq \emptyset$. For an initial point $x_{1} \in E$, define $C_{1}=C$ and the sequence $\left\{x_{n}\right\}$ in $C$ by

$$
\left\{\begin{array}{l}
z_{n}=J_{\lambda_{l, n}}^{A_{l}} \circ J_{\lambda_{l-1, n}}^{A_{l-1}} \circ \cdots \circ J_{\lambda_{1, n}}^{A_{1}} x_{n}, \\
u_{n}=T_{r_{m, n}}^{\theta_{m}} \circ T_{r_{m-1, n}}^{\theta_{m-1}} \circ \cdots \circ T_{r_{1, n}}^{\theta_{1}} z_{n}, \\
y_{n}=J^{-1}\left(\alpha_{n} J x_{1}+\beta_{n} J S^{n} x_{n}+\gamma_{n} J u_{n}\right), \\
C_{n+1}=\left\{v \in C_{n}: \phi\left(v, y_{n}\right) \leq \alpha_{n} \phi\left(q, x_{1}\right)+\left(1-\alpha_{n}\right) \phi\left(q, x_{n}\right)+\zeta_{n}\right\} \\
x_{n+1}=\Pi_{C_{n+1}} x_{1}
\end{array}\right.
$$

for all $n \geq 1$, where $\left\{\alpha_{n}\right\},\left\{\beta_{n}\right\}$ and $\left\{\gamma_{n}\right\}$ are the sequences in $(0,1)$ with $\alpha_{n}+\beta_{n}+\gamma_{n}=1$, $\zeta_{n}=\sup _{q \in \mathcal{F}}\left(k_{n}-1\right) \phi\left(q, x_{n}\right)$ and, for each $i=1,2,3, \ldots, m,\left\{r_{i, n}\right\} \subset[d, \infty)$ for some $d>0$. If $\lim _{n \rightarrow \infty} \alpha_{n}=0, \liminf _{n \rightarrow \infty} \beta_{n}<1$ and $\liminf _{n \rightarrow \infty} \lambda_{j, n}>0$ for each $j=1,2, \ldots, l$, then the sequence $\left\{x_{n}\right\}$ converges strongly to a point $\Pi_{\mathcal{F} x_{1}}$.

\section{Competing interests}

The author declare that they have no competing interests.

\section{Authors' contributions}

All authors contributed equally and significantly in writing this article. All authors read and approved the final manuscript.

\section{Author details}

${ }^{1}$ Department of Mathematics and Statistics, Faculty of Science, Thaksin University, Phatthalung, 93110, Thailand ${ }^{2}$ Department of Mathematics, Faculty of Science, King Mongkut's University of Technology Thonburi, Bangmod, Thrungkru, Bangkok, 10140, Thailand. ${ }^{3}$ Department of Mathematics Education and RINS, Gyeongsang National University, Chinju, 660-701, Korea.

\section{Acknowledgements}

This work was supported by Thaksin University Research Fund and YJ Cho was supported by the Basic Science Research Program through the National Research Foundation of Korea funded by the Ministry of Education, Science and Technology (NRF-2012-0008170) 


\section{References}

1. Fan, K: A minimax inequality and applications. In: Shisha, O (ed.) Inequality, vol. III, pp. 103-113. Academic Press, New York (1972)

2. Blum, E, Oettli, W: From optimization and variational inequalities to equilibrium problems. Math. Stud. 63, 123-145 (1994)

3. Martinet, B: Regularization d' inéquations variationelles par approximations successives. Rev. Fr. Autom. Inform. Rech. Opér. 4, 154-159 (1970)

4. Rockafellar, RT: Monotone operator and the proximal point algorithm. SIAM J. Control Optim. 14, $877-898$ (1976)

5. Cho, YJ, Kang, SM, Zhou, H: Approximate proximal point algorithms for finding zeroes of maximal monotone operators in Hilbert spaces. J. Inequal. Appl. 2008, Article ID 598191 (2008)

6. Ceng, LC, Liou, YC, Naraghirad, E: Iterative approaches to find zeros of maximal monotone operators by hybrid approximate proximal point methods. Fixed Point Theory Appl. 2011, Article ID 282171 (2011)

7. Güler, O: On the convergence of the proximal point algorithm for convex minimization. SIAM J. Control Optim. 29, 403-419 (1991)

8. Kohsaka, F, Takahashi, W: Strong convergence of an iterative sequence for maximal monotone operators in a Banach space. Abstr. Appl. Anal. 2004, 239-249 (2004)

9. Lewicki, G, Marino, G: On some algorithms in Banach spaces finding fixed points of nonlinear mappings. Nonlinear Anal. 71, 3964-3972 (2010)

10. Marino, G, Xu, HK: Convergence of generalized proximal point algorithm. Commun. Pure Appl. Anal. 3, 791-808 (2004)

11. Qin, X, Kang, SM, Cho, YJ: Approximating zeros of monotone operators by proximal point algorithms. J. Glob. Optim. 46, 75-87 (2010)

12. Saewan, S, Kumam, P: A hybrid iterative scheme for a maximal monotone operator and two countable families of relatively quasi-nonexpansive mappings for generalized mixed equilibrium and variational inequality problems. Abstr. Appl. Anal. 2010, Article ID 123027 (2010)

13. Yao, Y, Noor, MA: On convergence criteria of generalized proximal point algorithms. J. Comput. Appl. Math. 217, 46-55 (2008)

14. Yao, Y, Shahzad, N: Strong convergence of a proximal point algorithm with general errors. Optim. Lett. (2011). doi:10.1007/s11590-011-0286-2

15. Reich, S: A weak convergence theorem for the alternating method with Bregman distances. In: Kartsatos, AG (ed.) Theory and Applications of Nonlinear Operators of Accretive and Monotone Type, pp. 313-318. Dekker, New York (1996)

16. Saewan, S, Kumam, P: A modified Mann iterative scheme by generalized $f$-projection for a countable family of relatively quasi-nonexpansive mappings and a system of generalized mixed equilibrium problems. Fixed Point Theory Appl. 2011, 104 (2011)

17. Chang, SS, Joseph Lee, HW, Chan, CK, Zhang, WB: A modified Halpern-type iteration algorithm for totally quasi- $\boldsymbol{\phi}$-asymptotically nonexpansive mappings with applications. Appl. Math. Comput. (2011). doi:10.1016/j.amc.2011.12.019

18. Li, X, Huang, N, O'Regan, D: Strong convergence theorems for relatively nonexpansive mappings in Banach spaces with applications. Comput. Math. Appl. 60, 1322-1331 (2010)

19. Ofoedu, EU, Shehu, Y: Convergence analysis for finite family of relatively quasi nonexpansive mapping and systems of equilibrium problems. Appl. Math. Comput. (2011). doi:10.1016/j.amc.2011.03.147

20. Chang, SS, Joseph Lee, HW, Chan, CK: A new hybrid method for solving a generalized equilibrium problem, solving a variational inequality problem and obtaining common fixed points in Banach spaces, with applications. Nonlinear Anal. 73, 2260-2270 (2010)

21. Qin, X, Su, Y: Strong convergence theorems for relatively nonexpansive mappings in a Banach space. Nonlinear Anal. 67, 1958-1965 (2007)

22. Butnariu, D, Reich, S, Zaslavski, AJ: Asymptotic behavior of relatively nonexpansive operators in Banach spaces. J. Appl. Anal. 7, 151-174 (2001)

23. Censor, Y, Reich, S: Iterations of paracontractions and firmly nonexpansive operators with applications to feasibility and optimization. Optimization 37, 323-339 (1996)

24. Agarwal, RP, Cho, YJ, Qin, X: Generalized projection algorithms for nonlinear operators. Numer. Funct. Anal. Optim. 28 1197-1215 (2007)

25. Qin, X, Cho, YJ, Kang, SM: Convergence theorems of common elements for equilibrium problems and fixed point problems in Banach spaces. J. Comput. Appl. Math. 225, 20-30 (2009)

26. Zhou, H, Gao, G, Tan, B: Convergence theorems of a modified hybrid algorithm for a family of quasi- $\phi$-asymptotically nonexpansive mappings. J. Appl. Math. Comput. 32, 453-464 (2010)

27. Chang, SS, Joseph Lee, HW, Chan, CK, Yang, L: Approximation theorems for total quasi- $\phi$-asymptotically nonexpansive mappings with applications. Appl. Math. Comput. (2011). doi:10.1016/j.amc.2011.08.036

28. Alber, Yl: Metric and generalized projection operators in Banach spaces: properties and applications. In: Kartsatos, A (ed.) Theory and Applications of Nonlinear Operators of Accretive and Monotone Type, pp. 15-50. Dekker, New York (1996)

29. Alber, Yl, Reich, S: An iterative method for solving a class of nonlinear operator equations in Banach spaces. Panam. Math. J. 4, 39-54 (1994)

30. Cioranescu, I: Geometry of Banach Spaces, Duality Mappings and Nonlinear Problems. Kluwer Academic, Dordrecht (1990)

31. Kamimura, S, Takahashi, W: Strong convergence of a proximal-type algorithm in a Banach space. SIAM J. Optim. 13, 938-945 (2002)

32. Takahashi, W: Nonlinear Functional Analysis. Yokohama Publishers, Yokohama (2000)

33. Reich, S: Geometry of Banach spaces, duality mappings and nonlinear problems. Bull. Am. Math. Soc. 26(2), 367-370 (1992)

34. Wu, KQ, Huang, NJ: The generalized $f$-projection operator with an application. Bull. Aust. Math. Soc. 73, 307-317 (2006) 
35. Alber, Yl: Generalized projection operators in Banach spaces: properties and applications. In: Proceedings of the Israel Seminar, Ariel, Israel. Functional and Differential Equations, vol. 1, pp. 1-21 (1994)

36. Hudzik, H, Kowalewski, W, Lewicki, G: Approximative compactness and full rotundity in Musielak-Orlicz spaces and Lorentz-Orlicz spaces. Z. Anal. Anwend. 25, 163-192 (2006)

37. Fan, JH, Liu, X, Li, JL: Iterative schemes for approximating solutions of generalized variational inequalities in Banach spaces. Nonlinear Anal. 70, 3997-4007 (2009)

38. Deimling, K: Nonlinear Functional Analysis. Springer, Berlin (1985)

39. Takahashi, W, Zembayashi, K: Strong and weak convergence theorems for equilibrium problems and relatively nonexpansive mappings in Banach spaces. Nonlinear Anal. 70, 45-57 (2009)

40. Kohsaka, F, Takahashi, W: Existence and approximation of fixed points of firmly nonexpansive-type mappings in Banach spaces. SIAM J. Optim. 19, 824-835 (2008)

41. Saewan, S, Kumam, P: A strong convergence theorem concerning a hybrid projection method for finding common fixed points of a countable family of relatively quasi-nonexpansive mappings. J. Nonlinear Convex Anal. 13(2), 313-330 (2012)

42. Kohsaka, F, Takahashi, W: Existence and approximation of fixed points of firmly nonexpansive type mappings in Banach spaces. SIAM J. Optim. 19, 824-835 (2008)

43. Rockafellar, RT: On the maximality of sums of nonlinear monotone operators. Trans. Am. Math. Soc. 149, 75-88 (1970)

doi:10.1186/1687-1812-2013-199

Cite this article as: Saewan et al.: Iterative schemes for approximating solution of nonlinear operators in Banach spaces. Fixed Point Theory and Applications 2013 2013:199.

\section{Submit your manuscript to a SpringerOpen ${ }^{\circ}$ journal and benefit from:}

- Convenient online submission

- Rigorous peer review

- Immediate publication on acceptance

- Open access: articles freely available online

- High visibility within the field

- Retaining the copyright to your article 